\title{
Career Choice in Academic Medicine
}

\section{Systematic Review}

Sharon E. Straus, MD, MSC, FRCPC, ${ }^{1,2}$ Christine Straus, BEd, MA, ${ }^{2}$

Katina Tzanetos, MD, MSC, FRCPC, ${ }^{1}$ under the auspices of the International Campaign to Revitalise Academic Medicine

'Division of General Internal Medicine, University Health Network, Toronto, Cananda; ${ }^{2}$ Knowledge Translation Program, University of

Toronto/St. Michael's Hospital, Toronto, Canada.

OBJECTIVES: To review systematically the evidence about what factors influence the decision to choose or not choose a career in academic medicine.

DESIGN: A systematic review of relevant literature from 1990 to May 2005.

DATA SOURCES: Searches of The Cochrane Library, Medline (using Ovid and PubMed) from 1990 to May 2005, and EMBASE from 1990 to May 2005 were completed to identify relevant studies that explored the influential factors. Additional articles were identified from searching the bibliographies of retrieved articles.

SELECTION OF STUDIES: We attempted to identify studies that included residents, fellows, or staff physicians. No restrictions were placed on the study methodologies identified and all articles presenting empirical evidence were retrieved. For cohort, case-control, and crosssectional studies, minimum inclusion criteria were the presence of defined groups, and the ability to extract relevant data. For surveys that involved case series, minimum inclusion criteria were a description of the population, and the availability of extractable data. Minimum inclusion criteria for qualitative studies were descriptions of the sampling strategy and methods.

RESULTS: The search identified 251 abstracts; 25 articles were included in this review. Completion of an MD with a graduate degree or fellowship program is associated with a career in academic medicine. Of the articles identified in this review, this finding is supported by the highest quality of evidence. Similarly, the completion of research and publication of this research in medical school and residency are associated with a career in academic medicine. The desire to teach, conduct research, and the intellectual stimulation and challenge provided in academia may also persuade people to choose this career path. The influence of a role model or a mentor was reported by physicians to impact their decision making. Trainees' interest in academic medicine wanes as they progress through their residency.

CONCLUSIONS: In order to revitalize academic medicine, we must engage trainees and retain their interest throughout their training. Research opportunities for medical students, and fellowships or graduate training can meet this challenge and influence career choice. Initiatives to stimulate and maintain interest in academic medicine should be evaluated in prospective studies across multiple sites.

KEY WORDS: academic medicine; career choice.

DOI: $10.1111 /$ j.1525-1497.2006.00599.x

J GEN INTERN MED 2006; 21:1222-1229.

No conflicts of interest to declare.

Address correspondence and requests for reprints to Dr. Straus: Knowledge Translation Program, University of Toronto, 500 University Avenue, Suite 300, Toronto, ON, Canada M5G 1V7 (e-mail: sharon.straus@utoronto.ca).
$\mathrm{M}$ any threats to the future of academic medicine exist, including lack of leadership and innovation. ${ }^{1,2}$ Contributing to the concerns about the status of academic medicine is the perceived diminished workforce in academic medicine. ${ }^{3}$ Professional organizations from several countries have expressed concerns about the inability of the academic medicine workforce to keep pace with demands such as the increased intake of undergraduate students into medical schools. ${ }^{4,5}$ A recent survey of clinical academic staffing in UK medical schools found that $10 \%$ to $20 \%$ of medical professor and senior lecturer posts were vacant. ${ }^{5}$ This survey was conducted before the opening of 4 new medical schools with a planned increase of $60 \%$ in enrollment of undergraduates and thus these staffing levels are likely underestimated.

To comprehend this problem fully, attention must also be paid to what factors influence physicians to choose or reject academic medicine as a career path. There are some data exploring these factors for defined groups. In a survey of academic family physicians, stimulation received from learners, colleagues, and patients drew faculty into education. ${ }^{6}$ Perceived status of academic careers may also influence career choice. For example, several studies have shown that clinician educators at various universities are less likely to be at a higher rank than their colleagues in research and this may influence a decision to embark on this pathway. ${ }^{7,8}$ Some clinical researchers perceive that while their department chairs may voice support for their research, this may not be translated into tangible support, thus deterring interest in academia. ${ }^{9}$ Mentorship may also influence career choice and lack of appropriate role models and mentors may be particularly important factors in the relative paucity of women in academic medicine, particularly in leadership positions. ${ }^{10-12} \mathrm{~A}$ balance between personal and professional responsibilities may also influence this decision. Some clinicians note less time with family, ${ }^{13}$ lack of autonomy, ${ }^{14}$ and less leisure time ${ }^{15}$ in academic medicine as deterrents to this career path.

In order to develop a model for understanding capacity in academic medicine, it is necessary to first explore in detail what factors influence the decision to choose a career in academic medicine. This study was undertaken to review systematically the evidence in this field to further this understanding.

\section{METHODS}

Searches of The Cochrane Library, Medline (using Ovid and PubMed) from 1990 to May 2005, and EMBASE from 1990 to

Manuscript received December 12, 2005

Initial editorial decision February 20, 2006

Final acceptance June 21, 2006 
Table 1. Study Design Definitions

Case series: descriptive surveys that report on a select population without a comparison group

Case-control: surveys that identified physicians in academic medicine and those in private practice and then determined what factors influenced career choice

Cohort: studies that identified physicians with a defined exposure such as completion of an MD-PhD or fellowship and then determined the association with their career choice

Cross-sectional: surveys conducted at a single, common point in time that may have included people in academic medicine, and those not in academic medicine, and that assessed what factors influence career choice. In contrast to case-control studies, this study-type measures exposure (factors that may have influenced career choice such as completion of a $\mathrm{PhD}$ ) and outcome (academic career) at the same, single point in time

Qualitative research: studies that involve data from interviews, documents, and participant observation to understand and explain phenomena. Examples include grounded theory studies of data from interviews

May 2005 were completed to identify relevant studies that explored what factors influenced physicians to choose academic medicine. The search strategy used the terms "academic medicine," "medicin*," "career choice*," "clinician researcher*," "clinician scientist*," "clinician educator*," and "clinician teacher*." Additional articles were identified from searching the bibliographies of retrieved articles. It was decided to limit articles to those published after 1990 because it was felt that these articles would be most relevant to current practice in academic medicine. ${ }^{16}$ For example, reductions in trainee work hours that were implemented after 1990 in countries around the world were felt to have a significant impact on academic medicine and potentially the decision to enter academic medicine. ${ }^{1}$ No language restrictions were used. Details on the search strategies are available on request from the authors.

We attempted to identify studies that included residents, fellows, and/or staff physicians. No restrictions were placed on the study methodologies identified and all articles presenting empirical evidence were retrieved. We included studies with definitions of academic medicine that included a description of an academic affiliation (or faculty appointment) or some combination of research, teaching, and clinical practice. ${ }^{1}$

Two reviewers (S.E.S. and K.T.) independently reviewed and selected relevant publications that met the inclusion criteria from the search results. Disagreements were resolved by consensus. In cases of doubt, full-text articles were retrieved for review and discussion. Full-text articles of abstracts that met the inclusion criteria were retrieved.

S.E.S. and C.S. independently reviewed all full-text articles to confirm that inclusion criteria were met. The investigators also assessed study quality. A specially designed data collection form was used to extract data on study quality. Data were extracted from each article on the study design, sampling method, and assessment of outcome. For cohort, case-control, and cross-sectional studies, minimum inclusion criteria were the presence of defined groups, and the ability to extract relevant data. For surveys that involved case series, minimum inclusion criteria were a description of the population, target population that included residents, staff physicians, or fellows, and the availability of extractable data. Minimum inclusion criteria for qualitative studies were descriptions of the sampling strategy and methods. Definitions of the included study types appear in Table 1. Differences in assessment by the reviewers were resolved through discussion and a third investigator (K.T.) was available if necessary.

It is not possible (nor is it meaningful) to complete a statistical synthesis of the results of the studies and instead we narratively summarized the results using a strategy suggested by the Best Evidence Medical Education Collaboration and based on the validity of the individual studies. ${ }^{17}$ Studies were categorized independently by 2 investigators into themes arising from their results. For quantitative studies, only those themes that were found to be statistically significant were considered, or where these data were not available we considered those factors reported to be the most important to career choice. Where possible, a measure of association between influential factors on decision making, and academic medicine career choice was calculated as a relative risk (RR) or odds ratio (OR) and their 95\% confidence intervals (95\% CIs). Dominant themes from qualitative studies were included as reported by the authors of those studies.

\section{RESULTS}

Two hundred and fifty-one citations were identified from the literature search. A review of these abstracts led to retrieval of 85 full-text articles for assessment and 25 studies were subsequently identified for inclusion. The reasons for excluding articles were the absence of a description of methods used in a qualitative study $\left(1\right.$ study $\left.^{18}\right)$, the inability to extract data (3 studies ${ }^{19-21}$ ), the target population included medical students, program directors, or nonphysicians (10 studies ${ }^{22-31}$ ), the research question about career choice in academic medicine was not addressed ( 23 studies $^{32-54}$ ), the inclusion of an editorial or commentary without description of methods and results (22 studies $\left.^{3,12,55-74}\right)$, and insufficient details about the target population ( 1 study $^{75}$ ).

A description of the included articles is given in Appendix 1. Specialties of participants included general internal medicine, dermatology, psychiatry, obstetrics and gynecology, radiology, pediatrics, emergency medicine, neurology, and primary care.

Examination of the results of the studies identified several recurring themes. The main findings and a description of the study design from each of the 25 included studies are outlined in Appendix 2.

\section{Incentives to Enter Academic Medicine}

Completion of Graduate Degree/Fellowship or Research. Nine studies evaluated the impact of the completion of a graduate degree (including a Masters or $\mathrm{PhD}$ ) or research fellowship on the decision to enter academic medicine. ${ }^{76-84}$ Two articles described cohort studies, ${ }^{76,77} 3$ studies were cross-section$\mathrm{al},{ }^{78-80}$ and 4 were case series. ${ }^{81-84}$ Fang and Meyer ${ }^{76}$ completed a cohort study to evaluate the impact of the completion 
of a research training program for medical students on the likelihood of entering academic medicine. Awardees of the Howard Hughes Medical Institute Cloister Program (a 1-year research training program) and of their Medical Fellows Program were compared with unsuccessful applicants to these programs and to MD-PhD students who graduated during the same periods. Participation in the Cloister Program was associated with a faculty appointment (RR 1.44 [95\% CI 1.05 to 1.96]) compared with nonawardees. Similarly, completion of any MD-PhD program was associated with receiving a faculty appointment compared with nonawardees (RR 2.11 [95\% CI 1.71 to 2.6 ]) and with all other U.S. medical students (RR 4.18 [95\% CI 3.91 to 4.48$]$ ]).

Ledley and Lovejoy ${ }^{77}$ completed a cohort study of pediatric residents and found that completion of an MD-PhD or MD$\mathrm{MPH}$ was associated with an academic appointment (RR 1.30 [95\% CI 1.10 to 1.60$]$ ]). Similar results were found in a study of MD graduates from Harvard-MIT. ${ }^{78}$ A survey of neurology residents found that those with an MD-PhD expressed an interest in academic medicine more frequently than their colleagues with other degrees. ${ }^{79}$ However, Markert et al. ${ }^{80}$ found no relationship between completion of an $\mathrm{MD}-\mathrm{PhD}$ and an academic appointment.

In 3 surveys of graduates of $\mathrm{MD}-\mathrm{PhD}$ or fellowship programs, over $90 \%$ of graduates entered academia. ${ }^{81-83}$ In a survey of dermatology residents completing MD-PhD training, 20 of 26 anticipated a career in academic medicine. ${ }^{84}$

Completion of research and publication during medical school and residency are also associated with careers in academic medicine. Publishing during residency increased the likelihood of an academic career in a cohort study of 119 radiologists who graduated from a large academic training program (RR 3.75 [95\% CI 2.16 to 6.51$]$ ]) ${ }^{85}$ In a survey of several thousand radiologists, Cain et al. ${ }^{14}$ observed that academic radiologists were more likely to have performed and published research than their nonacademic colleagues but it is not possible to extract these data from their article. Hillman et al. ${ }^{86}$ found that academic radiologists had research articles published as medical students 1.4 times more often than did private practitioners $(P<.01)$. And, the greater the number of articles published, the greater the likelihood that an individual chose a research career. Surveys of emergency medicine residents found an association between research carried out in medical school ${ }^{87}$ (OR 1.22 [95\% CI 1.02 to 1.45$]$ ), or in residency $^{88}$ (RR 1.35 [95\% CI 1.15 to 1.57$]$ ) and an expressed interest in academic medicine.

Desire to Carry Out Research. Five studies explored the impact of a desire to conduct research on career choice including 4 quantitative studies ( 2 cross-sectional, 1 case-control, and 1 case series) and 1 qualitative study. Sanders et al. ${ }^{15}$ completed a study of emergency physicians and those in academic medicine ranked the value of research higher than those in private practice but it is not clear from their study whether this difference is statistically significant. And, more specialist registrars in academic posts in the United Kingdom felt that the challenge of research was an incentive to academic medicine than did their colleagues in NHS posts (RR 1.55 [95\% CI 1.33 to 1.79 ]). ${ }^{89}$ Sanders $^{88}$ found similar results among emergency medicine residents $(P<.0001)$. In a study of academic general practitioners, $57 \%$ of respondents viewed the challenge of research as an incentive to academia. ${ }^{90}$ However, none of these studies adjusted for potential confounders such as the completion of an MD-PhD program.

In a qualitative study of 26 radiology residents and 17 internal medicine residents, interviews suggested that emphasis on research was an incentive to considering academic medicine. ${ }^{91}$

Desire to Teach. Six studies described the impact of the desire to teach on the choice of a career in academic medicine. ${ }^{6,14,85,88,90,91}$ When asked to rate the influence of a desire to teach on their career decisions, it was ranked as the most important factor by participants in 3 studies that included academic and nonacademic physicians. ${ }^{14,85,88}$ Lee and Goldacre $^{90}$ found similar results in their study of academic general practitioners.

Two qualitative studies addressed this issue. ${ }^{6,91}$ Wood et al. ${ }^{91}$ found that less than half of the participants expressed an interest in academic medicine but of those who did, the ability to teach was 1 of the 3 most influential factors in their decision. Simpson et al. ${ }^{6}$ identified physician educators in family medicine who regarded themselves as satisfied with their career and interviewed 24 about how they made their career decision. Participants sought stimulation from their learners and valued their impact on training. They were drawn to teaching by its challenges and the hope that by impacting on training, they could "make the world better."

Intellectual Stimulation. Six studies addressed the impact of this factor on career choice. In a cross-sectional study of the first 14 classes of graduates from Wright State School of Medicine, no differences were noted in influential factors in decision making between those in academic medicine and private practice. ${ }^{80}$ Indeed, both groups ranked intellectual challenge as being important to their choice of an academic career. Rubeck et al. ${ }^{92}$ found that primary care physicians in academic medicine ranked intellectual stimulation as the most important incentive. In contrast, those in private practice ranked direct patient contact as the most important in their career decision. Similar results were found in a study of radiologists where $70 \%$ of those in academic medicine favored the intellectual challenge, compared with $37 \%$ of those in private practice $(P=.004){ }^{85}$ Specialist registrars felt that an intellectual environment was important in their career decision making but this was not significantly different between those in academic medicine and those in NHS posts. ${ }^{89}$

Eighty-eight percent of 309 academic general practitioners evaluated felt that a stimulating career was most important to their career decision and $60.2 \%$ rated the intellectual environment as an incentive to academia. ${ }^{90}$ In their qualitative study, Bergstrasser et al. ${ }^{91}$ found that academia was chosen because of its atmosphere in addition to its emphasis on research and the opportunity to teach.

Influence of a Mentor or Role Model. Four studies reported on the influence of a mentor or a role model. ${ }^{14,15,85,92}$ More academic radiologists claimed to be influenced by a role model than those in private practice. ${ }^{14,85}$ Primary care physicians in academic medicine described the influence of a role model or a mentor in their career decision and this was significantly different from those in private practice $(P<.05) .{ }^{91}$ And, more emergency physicians carrying out research in academic medicine noted the importance of a role model or a mentor in their decision making. ${ }^{87}$ 
Table 2. Disincentives to a Career in Academic Medicine

\begin{tabular}{|c|c|c|}
\hline Study & Study Design and Participants & Main Findings \\
\hline \multicolumn{3}{|l|}{ Qualitative studies } \\
\hline Brown et al. ${ }^{96}$ & $\begin{array}{l}\text { Focus groups-female medical students, fellows, } \\
\text { residents, junior, and senior faculty at Duke University } \\
\text { Medical Center, North Carolina in } 1997(n=78)\end{array}$ & $\begin{array}{l}\text { Academic medicine cannot accommodate diverse clinical } \\
\text { pathways }\end{array}$ \\
\hline \multirow[t]{3}{*}{ Wood et al. ${ }^{91}$} & Individual interviews-third-year and fourth-year & Dislikes research \\
\hline & residents and age-matched and gender-matched & Lack of autonomy \\
\hline & internal medicine residents from 2 institutions $(n=43)$ & Lower income \\
\hline Quantitative studies & & $\begin{array}{l}\text { Factors rated most important in influencing career choice (\% of } \\
\text { respondents) }\end{array}$ \\
\hline \multirow[t]{3}{*}{ Bergstrasser $^{95}$} & Cross-sectional survey-random sample of candidates & Low income $(65 \%)$ \\
\hline & who passed the qualifying exam for the American Board & Politics (30\%) \\
\hline & of Dermatology $(n=176)$ & Lack of autonomy $(25 \%)$ \\
\hline \multirow[t]{2}{*}{ Bilbey et al. ${ }^{14}$} & Cross-sectional survey-all members of the Canadian & Lower income in academic medicine (30\%) \\
\hline & $\begin{array}{l}\text { Association of Radiologists and all physicians who } \\
\text { completed the radiology residency program at the } \\
\text { University of British Columbia from } 1980 \text { to } 1990 \\
(n=1,648)\end{array}$ & Pressure to carry out research and publish (16\%) \\
\hline Cain et al. ${ }^{13}$ & $\begin{array}{l}\text { Cross-sectional survey-Fellows of the American College } \\
\text { of Obstetrics and Gynecology and obstetric and } \\
\text { gynecology residents taking the } 1998 \text { in-training exam } \\
(n=6,814)\end{array}$ & $\begin{array}{l}\text { Academic medicine too bureaucratic, } \\
\text { low income in academic medicine }\end{array}$ \\
\hline Doherty et al. ${ }^{79}$ & $\begin{array}{l}\text { Cross-sectional survey-Neurology program directors in } \\
\text { U.S. and Canada asked to invite residents in their } \\
\text { programs }(n=86)\end{array}$ & $\begin{array}{l}\text { Median debt-\$25 to } 49,999 \text { for those interested in AM; } \\
\$ 100 \text { to } 124,999 \text { for those uncertain; } \$ 50 \text { to } 74,999 \text { for those } \\
\text { not interested in AM }(P<.003)\end{array}$ \\
\hline \multirow[t]{3}{*}{ Feng and Ruzai-Shaprio 85} & Cohort-Radiologists who graduated between 1981 and & Lower financial rewards $(77 \%)$ \\
\hline & 2000 from Columbia University, New York $(n=79)$ & Low efficiency in academic institutions (54\%) \\
\hline & & Family influence (54\%) \\
\hline \multirow[t]{2}{*}{ Lee and Goldacre ${ }^{90}$} & Case series-General practitioners working in academic & Lower income $(81 \%)$ \\
\hline & departments in the United Kingdom ( $n=309)$ & $\begin{array}{l}\text { Competing pressures to do clinical service, teach, and } \\
\text { research }(38 \%)\end{array}$ \\
\hline
\end{tabular}

Duration and Stage of Training. Duration and stage of training may influence career choice. Using the results from their cross-sectional study of emergency medicine residents, Neacy et al. ${ }^{87}$ developed a logistic regression model for having an interest in academic medicine that found that senior residents had less interest in academic medicine than junior residents.

In their studies of obstetric and gynecology residents ${ }^{13}$ and primary care residents, ${ }^{93}$ investigators found that interest in academic medicine declined over training, with first-year residents being more interested than later-year residents. In particular, Leonard found that more female trainees lost interest over time compared with their male counterparts.

Gender. We were unable to find any studies that met inclusion criteria and that assessed the impact of gender on decision making. However, Reiser et al. ${ }^{94}$ observed in their cohort study that women who chose academic medicine were less likely to be married than those in private practice $(33.3 \%$ vs $75 \%$, $P=$.005).

Disincentives to Enter Academic Medicine. Seven studies described disincentives to academic medicine (Table 2). The most frequently cited disincentive to academic medicine was lower financial rewards. Feng and Ruzai-Shaprio ${ }^{85}$ surveyed 22 people who left academic medicine for private practice and they noted inadequate financial rewards, low efficiency in academic institutions, and family influence as the 3 most important factors in their decision to leave academic medicine. When asked why they left academic medicine, obstetricians/ gynecologists reported bureaucracy and low salary in academia as the primary motivators. ${ }^{13}$
Academic radiologists reported lower income, pressure to publish, and lack of autonomy as major deterrents to academic careers. ${ }^{14}$ Eighty-one percent of 309 academic general practitioners felt that financial disincentives existed in academic medicine. ${ }^{90}$ Moreover, $37 \%$ felt that pressure to provide clinical service, research, and teaching is a major disincentive to academic medicine. A cross-sectional study of dermatologists found income, politics, and lack of autonomy to be disincentives. ${ }^{95}$ One study of neurology residents found an association between level of debt and interest in academic medicine but this study did not provide details about the sampling frame or about potential confounders. ${ }^{79}$

Two qualitative studies explored deterrents to academic medicine. ${ }^{91,96}$ One study noted lack of autonomy and lack of financial rewards as deterrents to academic medicine. ${ }^{91}$ Focus groups conducted among women from 1 academic health center found that they perceived that academia was not able to accommodate diverse clinical pathways and did not facilitate the ability to balance competing roles. ${ }^{96}$

\section{DISCUSSION}

Attracting physicians into academic medicine is important for the continued advancement of medicine. ${ }^{3,63}$ Several studies have shown waning interest in this career path worldwide. ${ }^{3,12,63}$ In order to revitalize academic medicine, we need to consider what factors are influencing career choice. This study represents the first attempt to review systematically the available evidence and found that several factors may influence the decision to enter academic medicine.

Completion of an MD with a graduate degree or fellowship is associated with a career in academic medicine. Of the 
articles identified for this review, this finding is supported by the highest quality of evidence. Similarly, the completion and publication of research in medical school and residency are associated with a career in academic medicine. However, it is not clear what factors stimulate people to complete a $\mathrm{PhD}$ or research program. Residents were found to lose interest in academic medicine as their training progressed, which is of concern and should be explored in other studies to determine whether this is valid and if so, what factors contribute. For example, does the length of training, the lack of exposure to mentors or research opportunities, or a combination of these factors result in loss of interest? And, given the reduction in resident work hours over the last 5 years and studies showing that less time is spent in training, ${ }^{97}$ has this issue been addressed?

None of these data are sufficient to suggest causality but it may help administrators and educators consider strategies to enhance the attractiveness of this career. For example, initiatives to encourage medical students to complete research projects during their training could be developed and evaluated. Program directors and deans of medical schools could initiate programs (with input from students and residents) to introduce students to research at an early stage in training. Research electives (in basic and clinical research) could be offered throughout training. And, similar opportunities could be offered to provide experience in education and administration so that over the course of their training, students would complete at least 1 elective in each area. Moreover, exchanges between developed and developing countries should be mandated. For example, students in developed countries should complete at least 1 elective in a developing country. These efforts should be continued throughout residency in the hope that interest in academic medicine can be maintained. And, interdisciplinary collaborations should be encouraged in all of these activities as the successful career of the physician relies on these relationships.

The influence of a role model or mentor may also impact decision making. This influence was seen in training and in practice. Lack of mentorship was felt to impact negatively on research productivity and few formal mentorship programs have been implemented and evaluated. In an effort to improve academia, faculty development initiatives to enhance mentoring skills should be developed. ${ }^{98}$ Mentorship is underrecognized by administrators and appropriate academic compensation should be considered for excellent mentors.

Finally, administrators should develop strategies to address the disincentives to academic medicine such as enhancing the level of autonomy and career flexibility for academics and reducing the financial disparities. By working in academia, physicians accept lower financial rewards than their colleagues in private practice and until the value of their activities is recognized by society and the relevant funders, this will not change. However, administrators can work toward making the career more attractive by enhancing autonomy and career flexibility. Allowing clinicians to choose what duties they want to assume rather than mandating that all participate in teaching, research, and clinical care, and placing equivalent academic value on each of these areas may influence career choice. Certainly, the desire to teach, conduct research, and the intellectual stimulation and challenge provided in academia influence people to choose this career path while the pressure to be a "triple threat," requiring pro- ductivity in clinical work, research, and education, was seen to be a disincentive.

There are several limitations to this study. The quality of a systematic review is limited by the quality of the individual studies that are available. Many of these studies have small sample sizes and provide little detail on how the surveys were constructed. Similarly, details on methodology were often absent, including information about the sampling frame. And, most of the studies in this review are surveys, reflecting selfreport. Neither this evidence nor that from the other studies identified is sufficiently valid to suggest causation. ${ }^{69}$ For example, people who enroll in $\mathrm{PhD}$ programs are self-selected and thus it is not the PhD that influences career choice but rather some other individual characteristic.

Despite these limitations, this article does reflect the current state of our understanding about what factors influence career choice in academic medicine. It underscores the need for additional studies of higher quality and more robust study design to better understand the decision-making process. It also highlights a significant gap in our understanding about the impact of factors such as race and gender on career choice. This study is strengthened by the triangulation of study design that is available. For example, the impact of the desire to carry out research was reported in both quantitative and qualitative studies.

It is hoped that this review can stimulate innovative and collaborative work by encouraging administrators at academic institutions to enhance the factors that appear to increase interest in academic medicine, to address some of the disincentives to this career choice, and to evaluate these strategies rigorously. Some of the potential initiatives, as described above, are straightforward and could be implemented and evaluated simply. Other efforts to stimulate interest in academic medicine are more complex and require complete transformation of the current model. For example, 5 scenarios for the future of academic medicine were developed by the International Campaign to Revitalise Academic Medicine (ICRAM) after consultations with stakeholders worldwide (Appendix 3). ${ }^{99}$ These scenarios were developed to reinvigorate academic medicine and to make it more appealing to medical students and residents. For trainees, one of the most appealing of these scenarios is the "Fully Engaged" model in which all stakeholders (including patients, policymakers, health care professionals, students, and the public) are engaged with each other to advance academic medicine. In this model, medical education is community based and students and the public help drive the medical education and research agendas. Research is collaborative, conducted by diversely skilled individuals (including students and residents at various levels of training). Education, research, and governance of academic medicine are shared responsibilities involving all stakeholders. Using this approach, academic medicine could be energized and by implementing these transformative relationships, medical students and residents would become immediately and fully engaged with all aspects of academic medicine. This interest could be sustained throughout their training, enhancing their interest in a career in academic medicine.

While it may not be possible to implement the transformation of academic medicine as envisioned in the ICRAM scenarios, there are several research initiatives that could be implemented in the current model of academic medicine to facilitate engagement of trainees and academics. First, 
prospective studies of medical students should be conducted to explore what factors influence career choice. Surveys and qualitative assessment of participants could be completed yearly throughout their undergraduate and postgraduate training to determine interest in academic medicine. Second, this material should be used to develop strategies to enhance recruitment to academic medicine. Some of these strategies would be amenable to study in a randomized trial. For example, mentorship programs could be developed and evaluated using a randomized study design, measuring impact on selection of academic medicine, career satisfaction, and productivity. While it may not be feasible to randomize participants to an $\mathrm{MD}-\mathrm{PhD}$ program or alternative, a prospective cohort study could be completed including a cohort of people who have enrolled in a fellowship or graduate training program in research or education and comparing them with a cohort who have not participated in such a program and following them to determine impact on career choice. Third, all of the studies described above could be performed at single sites but rigor would be enhanced if they were completed across multiple sites. This endeavor would require collaboration at the highest levels, under leadership of the deans of medicine and organizations such as the Association of Professors of Medicine who are interested in preserving academic medicine. Given that medical schools and training programs are charged with training health care professionals for the future and with advancing clinical care, research, and education, they should feel compelled to participate in endeavors to stimulate interest in academic medicine and to mandate evaluation of these efforts. Indeed, why should educational interventions be considered different from other interventions such as drugs or care coordination strategies and not be subjected to the same valid evaluation in a randomized trial?

The future of academic medicine requires that we attract bright, enthusiastic candidates. This review provides an initial step to help guide this process. In addition to identifying some of the factors that may be relevant to career decision making, it highlights that more rigorous research, using higher quality study designs, must be completed to further understand what influences career choice in academic medicine. It is hoped that this review will lead to further efforts to revitalize academic medicine.

S.E.S. is supported by a Tier 2 Canada Research Chair and by the St. Michael's Hospital/University of Toronto Knowledge Translation Program. We thank Desiree Chanderbhan for her assistance with the preparation of this manuscript, Laure Perrier for her assistance with the development of the search strategies, and Kevin Thorpe, Merrick Zwarenstein, and Jocalyn Clark for their valuable comments on earlier drafts of this manuscript.

\section{REFERENCES}

1. International Working Party to Revitalise Academic Medicine. ICRAM: agenda setting. BMJ. 2004;329:787-9.

2. International Working Party to Revitalise Academic Medicine. Academic medicine: the evidence base. BMJ. 2004;329:789-92.

3. Savill J. More in expectation than in hope: a new attitude to training in clinical academic medicine. BMJ. 2000;320:630-3.

4. Gray J, Armstrong P. Academic health leadership: looking to the future. Clin Invest Med. 2003;26:315-26.

5. Council of Heads of Medical Schools. A survey of clinical academic staffing levels in UK medical and dental schools, 2001. Available at: www.chms.ac.uk/chms.pdf.
6. Simpson DE, Rediske VA, Beecher A, et al. Understanding the careers of physician educators in family medicine. Acad Med. 2001;76: 259-65.

7. Thomas PA, Diener-West M, Canto MI, et al. Results of an academic promotion and career path survey of faculty at the Johns Hopkins University School of Medicine. Acad Med. 2004;79:258-64.

8. Kelley WN, Stross JK. Faculty tracks and academic success. Ann Intern Med. 1992;116:654-9.

9. Oinonen MJ, Crowley WF, Moskowitz J, et al. How do academic health centers value and encourage clinical research. Acad Med. 2001;76:7006.

10. Jackson VA, Palepu A, Szalacha L, et al. Having the right chemistry: a qualitative study of mentoring in academic medicine. Acad Med. 2003;78:328-34.

11. McGuire LK, Bergen MR, Polan M. Career advancement for women faculty in a US school of medicine. Acad Med. 2004;79:319-25.

12. Abelson HT, Bowden RA. Women and the future of academic pediatrics. J Pediatr. 1990;116:829-33.

13. Cain JM, Schulkin J, Parisi V, et al. Effects of perceptions and mentorship on pursuing a career in academic medicine in obstetrics and gynecology. Acad Med. 2001;76:628-34.

14. Bilbey JH, Fache JS, Burhenne HJ. Are there predictors for future academic radiologists? A Canadian survey. Can Assoc Radiol J. 1992;43:369-73.

15. Sanders AB, Fulginiti JV, Witzke DB, Bangs KA. Characteristics influencing career decisions of academic and nonacademic emergency physicians. Ann Emerg Med. 1994;23:81-7.

16. Spencer SS. Careers in academic neurology. Ann Neurol. 1996;40:123-

17. Littlewood S, Ypinazar V, Margolis SA, et al. Early practical experience and the social responsiveness of clinical education: systematic review. BMJ. 2005;331:387-91.

18. Kalfoglou AL, Sung NW. What inspires clinical research trainees and keeps them on the path? J Invest Med. 2002;50:408-11.

19. Gunderman RB, Heitkamp DE, Kipfer HD, et al. Developing tomorrow's academic radiologists: a 3-month residency elective in education. Acad Radiol. 2003;10:650-6.

20. Osborn EH, Ernster VL, Martin JB. Women's attitudes toward careers in academic medicine at the University of California, San Francisco. Acad Med. 1992;67:59-62.

21. Solomon SS, Tom SC, Pichert J, et al. Impact of medical student research in the development of physician-scientists. J Invest Med. 2003;51:149-56.

22. Lubavin BV, Langdorf MI, Blasko BJ. The effect of emergency medicine residency format on pursuit of fellowship training and an academic career. Acad Emerg Med. 2004;11:938-43.

23. Buddeberg Fischer B, Klaghofer R, Abel T, Buddeberg $\mathbf{C}$. The influence of gender and personality traits on the career planning of Swiss medical students. Swiss Med Wkly. 2003;133:535-40.

24. Stern SA, Kim HM, Neacy $\mathbf{K}$, et al. The impact of environmental factors on emergency medicine resident career choice. Acad Emerg Med. 1999;6:262-70.

25. Braude RM. A descriptive analysis of National Library of Medicine-funded medical informatics training programs and the career choices of their graduates. Med Decision Making. 1991;11:33-7.

26. Huth JF. Impact of the Cancer Education Program on career paths of students. J Cancer Educ. 1991;6:145-51.

27. Goldacre MJ, Turner G, Lambert TW. Variation by medical school in career choices of UK graduates of 1999 and 2000. Med Educ. 2004;38:249-58.

28. Ranta M, Hussain SS, Gardiner Q. Factors that inform the career choice of medical students: implications for otolaryngology. J Laryngol Otol. 2002;116:839-41.

29. Erzurum VZ, Obermeyer RJ, Fecher A, et al. What influences medical students' choice of surgical careers. Surgery. 2000;128: 253-6.

30. Thornton J, Esposito F. How important are economic factors in choice of medical specialty? Health Econ. 2003;12:67-73.

31. Murdoch MM, Kressin N, Fortier L, et al. Evaluating the psychometric properties of a scale to measure medical students' career-related values. Acad Med. 2001;76:157-65.

32. Brotherton SE, Rockey PH, Etzel SI. US graduate medical education, 2003-2004. JAMA. 2004:292:1032-7.

33. Cooter R, Erdmann JB, Gonnella JS, et al. Economic diversity in medical education: the relationship between students' family income and 
academic performance, career choice, and student debt. Eval Health Prof. 2004;27:252-64.

34. Al-Jarallah KF, Moussa MA. Specialty choices of Kuwaiti medical graduates during the last three decades. J Cont Educ Health Prof. 2003;23:94-100

35. Erwin DO, Henry-Tillman RS, Thomas BR. A qualitative study of the experience of one group of African Americans in pursuit of a career in academic medicine. J Natl Med Assoc 2002 94:802-12.

36. Medina-Walpole A, Barker WH, Katz PR, et al. The current state of geriatric medicine: a national survey of fellowship-trained geriatricians, 1990 to 1998. J Am Geriatr Soc. 2002;50:949-55.

37. Clark JM, Hanel DP. The contribution of MD-PhD training to academic orthopaedic faculties. J Orthop Res. 2001;19:505-10.

38. Wallick MM, Cambre KM, Randall HM. Personality type and medical specialty choice. J LA State Med Soc. 1999;151:463-9.

39. Cravens DD, Campbell JD, Mehr DR. Why geriatrics? Academic geriatricians' perceptions of the positive, attractive aspects of geriatrics. Fam Med. 2000;32:34-41.

40. Tosi LL, Mankin JF. Ensuring the success of women in academic orthopaedics. Clin Orthop. 1998;356:254-63.

41. Ledley FD, Lovejoy FJ Jr. Prospects for academically trained pediatricians in academic medicine. Clin Invest Med. 1992;15:536-7.

42. Lovejoy FH, Ledley FD, Nathan DG. Academic careers: choice and activity of graduates of a pediatric residency program 1974-1986. Trans Am Clin Climatol Assoc. 1992;104:180-95; discussion 195-7.

43. Palepu A, Carr PL, Friedman RH, Ash AS, Moskowitz MA. Specialty choices, compensation and career satisfaction of underrepresented minority faculty in academic medicine. Acad Med. 2000;75:157-60.

44. Curtis P, Dickinson P, Steiner $\mathbf{J}$, et al. Building capacity for research in family medicine: is the blueprint faulty? Fam Med. 2003;35:124-30.

45. Ahn J, Watt CD, Greeley SA, Bernstein J. MD-PhD students in a major training program show strong interest in becoming surgeon-scientists. Clin Orthop. 2004;425:258-63.

46. Coyle YM, Aday LA, Battles JB, Hynan LS. Measuring and predicting academic generalists' work satisfaction: implications for retaining faculty. Acad Med. 1999;74:1021-27.

47. Buckley LM, Sanders K, Shih M, Hampton CL. Attitudes of clinical faculty about career progress, career success and recognition, and commitment to academic medicine. Arch Intern Med. 2000;160:2625-9.

48. Campos-Outcalt D, Senf J, Watkins AJ, Bastacky S. The effects of medical school curricula, faculty role models, and biomedical research support on choice of generalist physician. Acad Med. 1995;70:611-9.

49. Brodgon BG, Heveron ED, Diamond JJ. Attitudes of American radiologists toward their practices: present and future. Am J Radiol. 1990;154:867-9.

50. Bland CJ, Meurer LN, Maldonado G. Determinants of primary care specialty choice: a non-statistical meta-analysis of the literature. Acad Med. 1995;70:620-41

51. Friedman CP, Slatt LM. New results relating the Myers-Briggs Type indicator and medical specialty choice. J Med Educ. 1988;63:325-7.

52. Moss PH, Lambert TW, Goldacre MJ, Lee P. Reasons for considering leaving UK medicine: questionnaire study of junior doctors' comments. BMJ. 2004;329:1263.

53. Ward AM, Kamien M, Lopez DG. Medical career choice and practice location: early factors predicting course completion, career choice and practice location. Med Educ. 2004;38:239-48.

54. Gerrity MS, Pathman DE, Linzer M, et al. Career satisfaction and clinician-educators: the rewards and challenges of teaching. JGIM. 1997;12(suppl 2):S90-S97.

55. Devonald MAJ. Careers in academic medicine. Clin Med. 2004;4:284-5.

56. Brem H, Amundson E. Preparing Hopkins medical students for a career in academic medicine. Surgery. 2003;134:414-5.

57. Todd RF. A guide to planning careers in hematology and oncology. Am Soc Hematol Educ Program 2001:499-506.

58. Gunderman RB. Today's radiology redient and tomorrow's academic radiologist. AJR. 2001;177:1277-80

59. Rubenstein DS, Blauvelt A, Chen SC, Darling TN. The future of academic dermatology in the United States: report on the resident retreat for future physician-scientists, June 15-17, 2001. J Am Acad Dermatol. 2002;47:300-3.

60. Cavalieri TA, Basehore P, Perweiller E, Chopra A. Training osteopathic geriatric academicians: impact of a model geriatric residency program. J Am Osteopath Assoc. 1999;99:371-6.

61. Spencer SS. Careers in academic neurology, 1996. Ann Neurol. 1996;40:123-7. Comment in Ann Neurol 1997;41(2):283-4.
62. Griggs RC. Careers in academic neurology in the decade of the brain. Ann Neurol. 1994;35:753-8.

63. Watanabe M. How to attract candidates to academic medicine. Clin Invest Med. 1992;15:204-15.

64. Martin CA, DeMoss KL. The development of the woman child psychiatry researcher-a review. J Am Acad Child Adolesc Psychiatry. 1991;30:1009-14

65. Chesney RW. The impact of medical school loans and the promise of loan repayment on entry into a pediatric academic career. Arch Pediatr Adolesc Med. 2001;155:1296-7.

66. Reynolds T. Are physician-scientists a vanishing breed? J Natl Cancer Inst. 2001;93:490-1

67. Zemlo TR, Garrison HH, Partridge NC, Ley TJ. The physician-scientist: career issues and challenges at the year 2000. FASEB J. 2000;14:22130.

68. Perry CL. How renowned researchers were initiated into the world of research. Am J Health Behav. 2003;27:564-73.

69. Pathman DE, Agnew CR. Querying physicians' beliefs in career choice studies: the limitations of introspective causal reports. Fam Med. 1993;25:203-7.

70. Rashid A, Allen J, Styles B, Gray DP. Careers in academic general practice: problems, constraints, and opportunities. BMJ. 1994;309:1270-2.

71. Allen I. Factors affecting career choices in medicine. Clin Obstet Gynecol. 1999;13:323-36.

72. Hilton S. Careers in academic practice. BMJ. 1995;310:262.

73. MacDonald R. Survey shows serious shortage of medical academics in the UK. BMJ. 2002;324:446.

74. Morrison J. Influences before and during medical on career choices. Med Educ. 2004;38:230-1.

75. Fox M. Medical student indebtedness and the propensity to enter academic medicine. Health Econ. 2003;12:101-12.

76. Fang D, Meyer RE. Effect of two Howard Hughes Medical Institute research training programs for medicals students on the likelihood of pursuing research careers. Acad Med. 2003;78:1271-80.

77. Ledley FD, Lovejoy FH Jr. Factors influencing the interests, career paths, and research activities of recent graduates from an academic, pediatric residency program. Pediatrics. 1993;92:436-41.

78. Abelmann WH, Nave BD, Wilkerson L. Generation of physician-scientists manpower: a follow-up study of the first 294 graduates of the Harvard-MIT Program of Health Sciences and Technology. J Invest Med. 1997;45:272-5.

79. Doherty MJ, Schneider AT, Tirschwell DL. Will neurology residents with large student loan debts become academicians? Neurology. 2002;58:495-7.

80. Markert RJ, Part HM, Vetter DK. Predictors of careers in academic medicine for graduates of a community-based, primary-care-oriented medical school. Acad Med. 1998;73:790-3.

81. Frieden C, Fox BHJ. Career choices of graduates from Washington University's Medical Scientist Training Program. Acad Med. 1991;66:162-4.

82. McClellan DA, Talalay P. MD-PhD training at the Johns Hopkins University School of Medicine, 1962-1991. Acad Med. 1992;67:36-41.

83. Simon SR, Shaneyfelt TM, Collins MM, et al. Faculty training in general internal medicine: a survey of graduates from a research-intensive fellowship program. Acad Med. 1999;74:1253-5.

84. Prystowsky JH. Factors influencing the pursuit of careers in academic medicine: a survey of $\mathrm{MD}-\mathrm{PhD}$ residents in dermatology programs in the United States. J Invest Dermatol. 1992;98:125-7.

85. Feng L, Ruzai-Shaprio C. Factors that influence radiologists' career choices. Acad Radiol. 2003;10:45-51.

86. Hillman BJ, Fajardo LL, Witzke DB, et al. Influences affecting radiologists' choices of academic or private practice careers. Radiology. 1990; 174:561-4.

87. Neacy K, Stern SA, Kim HM, Dronen SC. Resident perception of academic skills training and impact on academic career choice. Acad Emerg Med. 2000;9:1408-15

88. Sanders AB, Fulginiti JV, Witzke DB. Factors influencing resident career choices in emergency medicine. Ann Emerg Med. 1992;21: 47-52.

89. Goldacre M, Stear S, Richards R, Sidebottom E. Junior doctors' views about careers in academic medicine. Med Educ. 1999;33: 318-26.

90. Lee $\mathbf{P}$, Goldacre $\mathbf{M}$. Views of general practitioners in academic posts about careers in academic general practice: a national survey. Educ Primary Care. 2002;13:465-71. 
91. Wood PS, Altmaier EM, Franken Jr EA, et al. Factors influencing choice of academic or practice careers in radiology. Invest Radiol. 1990;25:675-7.

92. Rubeck RF, Donnelly MB, Jarecky RM, et al. Demographic, educational, and psychosocial factors influencing the choices of primary care and academic medical careers. Acad Med. 1995;70:318-20.

93. Leonard JC, Ellsbury KE. Gender and interest in academic careers among first- and third-year residents. Acad Med. 1996;71:502-4.

94. Reiser LW, Sledge WH, Fenton W, Leaf P. Beginning careers in academic psychiatry for women-"Bermuda Triangle"? Am J Psychiatry. 1993; 150:1392-7.

95. Bergstrasser PR. Perceptions of the academic environment: a national survey. J Am Acad Dermatol. 1991;25:1092-6.

\section{Supplementary Material}

The following supplementary material is available for this article online at www.blackwell-synergy.com

\section{Appendix 1.}

Appendix 2.

Appendix 3.
96. Brown AJ, Swinyard W, Ogle $\mathbf{J}$. Women in academic medicine: a report of focus groups and questionnaires, with conjoint analysis. J Women's Health (Larchmt). 2003;12:999-1008.

97. Underwood SM, McIndoe AK. Influence of changing work patterns on training in anaesthesia: an analysis of activity in a UK teaching hospital from 1996 to 2004. Br J Anaesth. 2005;95:616-21.

98. Sambunjak D, Straus SE, Marusic A. Impact of mentorship on career development: systematic review. JAMA. (in press).

99. Awasthi S, Beardmore J, on behalf of the International Campaign to Revitalise Academic Medicine, et al. Five futures for academic medicine. PLoS Med. 2005;2:606-13. 